We found that the post-operative hypoxaemia was rapidly reversed by breathing $30 \%$ oxygen in normals, but that in the atelectasis cases, although there was an increase in arterial oxygen saturation, it was not possible to achieve normal saturation and the rise was much slower. This is because, although $30 \%$ oxygen will raise the alveolar $\mathrm{Po}_{2}$ in hypoventilated alveoli sufficiently to achieve normal saturation of the pulmonary capillary blood, it will not raise the saturation of blood flowing through unventilated atelectatic areas.

It is difficult to recognize hypoxaemia from the presence of cyanosis until the $\mathrm{O}_{2}$ saturation has fallen to about $80 \%$ (Comroe and Botelho, 1947), and as it may not be possible to measure the arterial oxygen saturation it is logical to administer oxygen routinely after the operation to those patients who are least able to withstand hypoxaemia-that is, those in the older age-groups and those who have evidence of respiratory, cardiac, or cerebrovascular disease. As $30 \%$ $\mathrm{O}_{2}$ will correct the hypoxaemia this concentration is preferable to $100 \% \mathrm{O}_{2}$ because when the alveoli contain a high proportion of absorbable gas atelectasis may be more apt to occur. When there is post-operative atelectasis, serious hypoxaemia occurs which is often unrecognized. Therefore, in addition to the treatment of this complication with physiotherapy, bronchodilators, antibiotics, and mucolytic agents, oxygen therapy should always be given.

Although pulmonary mechanical function was considerably impaired, respiratory acidosis (raised arterial $\mathrm{PCO}_{2}$ ) did not occur-instead the arterial $\mathrm{PCO}_{2}$ levels were slightly reduced. This tendency towards a mild respiratory alkalosis might result from anoxic stimulation of the carotid and aortic bodies, but this does not occur until the arterial $\mathrm{Po}_{2}$ falls to about $60 \mathrm{~mm} . \mathrm{Hg}$; moreover, the lowest arterial $\mathrm{PCO}_{2}$ readings did not occur on the days when the arterial $\mathrm{Po}_{2}$ was lowest. The arterial $\mathrm{PCO}_{2}$ levels, the whole-blood buffer base, $\left(\mathrm{HCO}_{3}{ }^{-}\right) \mathrm{p}$, and the arterial $\mathrm{T} . \mathrm{CO}_{2}$ appeared to be interrelated, as they were all most reduced on the same post-operative days, and it seems probable that the mild metabolic acidosis was secondary to hyperventilation.

\section{Summary}

The effect on pulmonary physiology of a major abdominal operation (partial gastrectomy) was studied in 32 patients by measuring ventilatory function, blood-gas levels, and the acid-base balance. Eighteen patients developed postoperative atelectasis-the only difference between these patients and those who did not develop pulmonary complications being that $66 \%$ were bronchitic compared with $21 \%$ of the uncomplicated group. The changes in pulmonary physiology were similar in both groups, but were in general more severe in the complicated group. There was marked restrictive ventilatory impairment, maximal on the first postoperative day, and the complicated group, in addition, showed reversible airways obstruction during the first three postoperative days. There was arterial hypoxaemia lasting at least five days, and this was more marked in the complicated group ; but in neither group did it strictly parallel the reduction in pulmonary mechanical function and it was thought to be due to regional alveolar hypoventilation. Hypercapnia did not occur, and the tendency to overventilation and hypocapnia was compensated for by the development of a mild postoperative metabolic acidosis.

Our thanks are due to Professor W. C. Wilson and the members of the department of surgery for their co-operation and for allowing us to examine their patients. We would also like to thank Professor H. A. F. Dudley for the stimulating interest he showed in these experiments. Our sincere thanks are also due to the Vaughan Hudson Clinical Trust and the Mary Kinross Clinical Trust for their generous help in the purchase of apparatus.

\section{REFERENCES}

Ciba Symposium (1959). Thorax, 14, 286.

Comroe, J. H., jun., and Botelho, S. (1947). Amer. F. med. Sa., 214, 1. Dill, D. B., and Forbes, W. H. (1941). Amer. 7. Physiol., 132, 685.

Nunn, J. F., and Payne, J. P. (1962). Lancet, 2, 631.

Palmer, K. N. V. (1961). Ibid., 1, 191.

Singer, R. B., and Hastings, A. B. (1948). Medicine (Baltimore), 27, 223.

\title{
Hypoxaemia After Crush Injury of the Chest
}

\author{
J. G. WHITWAM,* M.B., F.F.A. R.C.S. ; J. NORMAN, $†$ M.B., F.F.A. R.C.S.
}

Brit. med.F., 1964, 1, 349-351

It is often assumed that hypoxaemia following chest injury is due to inadequate alveolar ventilation and is therefore associated with carbon-dioxide retention. Harley (1961) and Barrett (1960) have discussed the factors which may cause hypoventilation in these patients. In addition, Harley (1961) has suggested that in patients with chest injury the pathological changes in the lung parenchyma may lead to a further reduction in the oxygenation of the arterial blood.

For many years oxygen therapy combined with measures to increase alveolar ventilation, such as clearing of secretions from the airways and relief of pulmonary tamponade, ${ }^{1}$ have been regarded as essential in the treatment of such patients. More recently, further procedures aimed at achieving adequate

\footnotetext{
* Senior Registrar, Department of Anaesthetics, The General Infirmary at Leeds.

$†$ Registrar, Department of Anaesthetics, The General Infirmary at Leeds.

"The term " pulmonary tamponade" refers to the reduction of total hung volume due to the presence of gas, fluid, or abdominal viscera in the pleural cavities.
}

alveolar ventilation have been advocated, such as tracheostomy and the use of intermittent positive-pressure respiration (I.P.P.R.) (Avery et al., 1956 ; Griffiths, 1960 ; Sellors, 1961).

Evidence is presented in this paper to show that when therapeutic measures result in adequate alveolar ventilation, as judged by the arterial carbon-dioxide tension $\left(\mathrm{P}_{\mathrm{a}} \mathrm{CO}_{2}\right)$, hypoxaemia, measured by percentage saturation of the arterial blood with oxygen $\left(\mathrm{S}_{\mathrm{a}} \mathrm{O}_{2}\right)$, may still be present. Some evidence is also presented regarding the probable cause of the arterial desaturation.

\section{Material}

Arterial blood-gas analyses have been performed on nine patients with crush injuries of the chest admitted to this centre.

Case 1.-Man aged 54. Multiple fractures of left ribs associated with paradoxical respiration. Other severe skeletal injuries. 
Tracheostomy performed eight hours and I.P.P.R. instituted nine hours after injury. Survived.

Case 2.-Man aged 56. Previous history of bronchitis. Multiple fractures of right ribs associated with paradoxical respiration. Mild head injury and other severe skeletal and abdominal injuries. Tracheostomy performed four hours and I.P.P.R. instituted 24 hours after injury. He became increasingly difficult to ventilate, and it was not possible to clear the small airways of secretions. After the second day the $\mathrm{P}_{\mathrm{a}} \mathrm{CO}_{2}$ as determined by the rebreathing technique (Campbell and Howell, 1960) was above normal limits. Died on the fifth day.

Case 3.-Man aged 40. Bilateral fractures of the ribs with a flail anterior segment of chest wall. Tracheostomy performed two hours and I.P.P.R. started 24 hours after injury. Survived.

Case 4.-Man aged 73. Previous history of bronchitis. Multiple fractures of right ribs associated with paradoxical respiration. Tracheostomy performed 24 hours and I.P.P.R. instituted 168 hours after injury. Ventilated for 22 days ; 11 days after coming off the ventilator death occurred suddenly from myocardial infarction.

Case 5.-Woman aged 49. Multiple fractures of right ribs associated with paradoxical respiration. Mild head injury. Tracheostomy performed two hours and I.P.P.R. instituted 10 hours after injury. Survived.

Case 6.-Man aged 46. Multiple fractures of right ribs associated with haemopneumothorax and haemopneumopericardium. Severe limb and abdominal injuries. Tracheostomy performed four hours after injury. Died 120 hours after injury from the effects of multiple injuries associated with multiple fat emboli.

Case 7.-Woman aged 31. Fractures of lower sternum and associated costal cartilages. Gross perineal lacerations. Tracheostomy performed six hours and I.P.P.R. started 51 hours after injury. Survived.

Case 8.- Man aged 49. Fractures of body of sternum and associated costal cartilages. Tracheostomy performed one hour after injury and I.P.P.R. instituted at the same time. Survived.

Case 9.-Woman aged 45. Multiple fractures of right ribs associated with paradoxical respiration. I.P.P.R. instituted two hours after injury, using general anaesthesia and an endotracheal tube. Tracheostomy performed seven hours after injury. Survived.

\section{Methods}

Arterial blood samples were obtained either by an indwelling radial artery cannula or by femoral artery puncture. $\mathrm{P}_{\mathrm{a}} \mathrm{CO}_{2}$ was determined by the interpolation technique of Andersen et al. (1960), using the micro-equipment described by Astrup (1959). $\mathrm{S}_{2} \mathrm{O}_{2}$ was determined by a photoelectric technique, using a Kipp haemoreflector. Inspired oxygen concentrations $\left(\mathrm{F}_{1} \mathrm{O}_{2}\right)$, when determined, were measured with a Beckman oxygen analyser (model D-2), sampling from the inspiratory limb of the ventilator tubing, and expired minute-volumes were measured with a Wright anemometer inserted into the circuit close to the tracheostomy. So far as could be ascertained clinically, all patients were in a steady state at the time of arterial blood sampling with the exception of sample 1 in Cases 2 and 7 and sample 3 in Case 3.

Oxygen Therapy.-In those patients breathing spontaneously through a tracheostomy, when oxygen was administered the inspired oxygen concentration was of the order $40-50 \%$, except in Case 6, where the concentration was approximately $80 \%$. When I.P.P.R. was instituted oxygen was added via the air intakes of the Blease or the Smith-Clarke ventilator. Subsequent investigation has shown that the inspired oxygen concentration could not have been in excess of $50 \%$ and was probably of the order $30-35 \%$. In Cases 8 and 9, oxygen when administered was added to the air intake of the Cape ventilators; the inspired oxygen concentration was changed between the two arterial samples in each case.

\section{Results}

The results of the arterial blood-gas analyses are shown in Tables I and II and may be summarized as follows. (1) During the first few days after injury, alveolar ventilation, as judged by the $\mathrm{P}_{\mathrm{a}} \mathrm{CO}_{2}$, was adequate, provided the airway was unobstructed and in the absence of pulmonary tamponade. (2) In the absence of oxygen therapy, although alveolar ventilation was adequate, the $\mathrm{S}_{2} \mathrm{O}_{2}$ was reduced. When oxygen was added to the inspired gases there was a significant improvement in the $\mathrm{S}_{\mathrm{a}} \mathrm{O}_{2}$.

TABLE I.-Results of Arterial Blood-Gas Analysis (Cases 1-7)

\begin{tabular}{|c|c|c|c|c|c|}
\hline $\begin{array}{l}\text { Case } \\
\text { No. }\end{array}$ & Sample & $\begin{array}{c}\text { Hours after } \\
\text { Injury }\end{array}$ & $\begin{array}{l}\text { Mode of } \\
\text { Respiration }\end{array}$ & $\underset{(\mathrm{mm} . \mathrm{Hg})}{\mathrm{P}_{\mathrm{aCO}}}$ & $\begin{array}{l}\mathrm{S}_{\mathrm{a}} \mathrm{O}_{2} \\
(\%)\end{array}$ \\
\hline 1 & 1 & 26 & I.P.P.R., O. & 24 & 94 \\
\hline 2$\}$ & $1^{*}$ & $\begin{array}{r}3 \\
24\end{array}$ & $\begin{array}{l}\text { S.R. } \\
\text { S.R., T. }\end{array}$ & $\begin{array}{l}57 \\
27\end{array}$ & $\begin{array}{l}81 \\
73\end{array}$ \\
\hline 3 & $\begin{array}{l}1 \\
2 \\
3 \dagger \\
4\end{array}$ & $\begin{array}{r}2 \\
4 \\
24 \\
96\end{array}$ & $\begin{array}{l}\text { S.R. } \\
\text { S.R., T., O. } \\
\text { S.R., T., O. } \\
\text { I.P.P.R., O. }\end{array}$ & $\begin{array}{l}36 \\
40 \\
46 \\
33\end{array}$ & $\begin{array}{l}84 \\
88 \\
72 \\
90\end{array}$ \\
\hline 4 & $\begin{array}{l}1 \\
2\end{array}$ & $\begin{array}{l}48 \\
72\end{array}$ & $\begin{array}{l}\text { S.R., T. } \\
\text { S.R., T. }\end{array}$ & $\begin{array}{l}37 \\
26\end{array}$ & $\begin{array}{l}84 \\
80\end{array}$ \\
\hline 5 & $\frac{1}{2}$ & $\begin{array}{r}5 \\
22\end{array}$ & $\begin{array}{l}\text { S.R., T. } \\
\text { I.P.P.R., O. }\end{array}$ & $\begin{array}{l}45 \\
37\end{array}$ & $\begin{array}{l}95 \\
88\end{array}$ \\
\hline 6 & $\begin{array}{l}1 \\
2 \\
3\end{array}$ & $\begin{array}{r}82 \\
83 \\
107\end{array}$ & $\begin{array}{l}\text { S.R., T. } \\
\text { S.R., T., O. } \\
\text { S.R., T., O. }\end{array}$ & $\frac{36}{37}$ & $\begin{array}{l}75 \\
97 \\
92\end{array}$ \\
\hline 7\{ & $\frac{1 \neq}{2}$ & $\begin{array}{l}50 \\
54\end{array}$ & $\begin{array}{l}\text { S.R., T. } \\
\text { I.P.P.R., O. }\end{array}$ & $\begin{array}{l}37 \\
30\end{array}$ & $\begin{array}{l}58 \\
88\end{array}$ \\
\hline
\end{tabular}

S.R. = Spontaneous respiration. T. $=$ Tracheostomy. $\quad$ O.=-Oxygen added to inspired gases.

* Airway partially obstructed with blood and secretions. $\dagger$ Tension pneumothorax present. $\ddagger$ This may have been a venous-blood sample, but the patient was TABLE II.-Results of Arterial Blood-Gas Analysis (Cases 8-9)

\begin{tabular}{|c|c|c|c|c|c|c|}
\hline $\begin{array}{l}\text { Case } \\
\text { No. }\end{array}$ & Sample & $\begin{array}{l}\text { Hours } \\
\text { after } \\
\text { Injury }\end{array}$ & $\begin{array}{c}\text { Minute- } \\
\text { volume } \\
\text { (litres/min.) }\end{array}$ & $\begin{array}{l}\mathrm{F}_{1} \mathrm{O}_{2} \\
(\%)\end{array}$ & $\underset{\left(\mathrm{mm} \cdot \mathrm{H}_{\mathrm{g}}\right)}{\mathrm{PaCO}_{2}}$ & $\begin{array}{l}\mathrm{S}_{\mathrm{a}} \mathrm{O}_{2} \\
(\%)\end{array}$ \\
\hline 8 & $\begin{array}{l}1 \\
2\end{array}$ & ${ }_{10}^{8 \frac{1}{2}}$ & $\begin{array}{l}23 \\
20\end{array}$ & $\begin{array}{l}40 \\
60\end{array}$ & $\begin{array}{l}23 \\
22\end{array}$ & $\begin{array}{l}82 \\
92\end{array}$ \\
\hline 9 & $\begin{array}{l}1 \\
2\end{array}$ & $\begin{array}{l}24 \\
26\end{array}$ & $\begin{array}{l}16 \\
16 \cdot 4\end{array}$ & $\begin{array}{l}45 \\
21\end{array}$ & $\begin{array}{l}26 \\
22\end{array}$ & $\begin{array}{l}96 \\
88\end{array}$ \\
\hline
\end{tabular}

Both patients were on I.P.P.R. at the times when samples were taken.

\section{Discussion}

Three principal factors may contribute to a reduction in the percentage arterial oxygen saturation in patients with disordered respiratory function: inadequate alveolar ventilation, disturbances of ventilation-blood-flow relationships, and frank " rightto-left " shunting of blood.

In the patients reported in this paper in whom measurement of the $\mathrm{P}_{\mathrm{a}} \mathrm{CO}_{2}$ was made after tracheostomy, with adequate clearing of chest secretions and in the absence of pulmonary tamponade, alveolar ventilation was adequate. The concept that respiratory distress associated with paradoxical respiration is due to pendulum-like movement of gas from one lung to the other, leading to carbon-dioxide retention and hypoxia, has been shown to be erroneous (Maloney et al., 1961). The findings reported hére of normal or below-normal arterial carbon-dioxide tensions in patients with paradoxical respiration are in keeping with this experimental work. Thus after tracheostomy alveolar hypoventilation could be excluded as a factor causing hypoxaemia.

In these patients oxygen therapy led to an increase in the $\mathrm{S}_{\mathrm{a}} \mathrm{O}_{2}$, but normal saturation was not always restored. This suggests that, although alteration in ventilation-perfusion relationships in the lungs may have been in part responsible for the hypoxaemia, in some patients there was a considerable amount of frank right-to-left shunting of blood.

After severe trauma, hypoxaemia resulting from damage to the lungs will contribute to the reduction in oxygen availability to the tissues caused by circulatory factors-for example, reduction in the circulating blood volume and cardiac output, haemodilution, disturbances in the flow properties of the blood (Gelin, 1961), and systemic fat embolization.

The results presented here have two important practical applications. (1) When assessing the respiratory state of patients 
with crush injuries of the chest it cannot be assumed that oxygenation is adequate on the basis of the finding of a normal $\mathrm{P}_{\mathrm{a}} \mathrm{CO}_{2}$. (2) In these patients the inspired gases should be enriched with oxygen no matter what the mode or amount of ventilation. Even then hypoxaemia may still be present. Further therapy should aim at promoting expansion of the lungs and at restoring to normal the circulating blood volume and the oxygen-carrying capacity of the blood.

\section{Summary}

Arterial blood-gas analyses have been performed on nine patients who had sustained chest injuries. After tracheostomy and in the absence of pulmonary tamponade the lungs were capable of maintaining normal or subnormal carbon dioxide tensions, but in all cases there was a reduction in the percentage saturation with oxygen of the arterial blood, and in some patients this was not corrected fully with oxygen therapy. Some of the implications of these findings are discussed.
We wish to thank Professor J. C. Goligher, the late Mr. M. C. Oldfield, Mr. A. B. Pain, Dr. F. M. Parsons, Mr. H. S. Shucksmith, Mr. F. G. Smiddy, and Mr. D. A. Watson, under whose care these patients were admitted, for permission to publish; Dr. J. J. L. Ablett and Dr. D. W. Clark, who supervised their respiratory management ; Mr. G. H. Wooler, Director of the Thoracic Surgical Department, in whose laboratories the blood-gas analyses were performed; and Dr. V. A. Grimshaw for advice in the preparation of this paper.

\section{REFERENCES}

Andersen, O. S., Engel, K., Jørgensen, K., and Astrup, P. (1960). Scand. f. clin. Lab. Invest., 12, 172.

Astrup, P. (1959). In Symposium on pH and Blood Gas Measuremens. edited by $\mathrm{R}$. F. Woolmer. Churchill, London.

Avery, E. E., Mörch, E. T., and Benson, D. W. (1956). 7. thorac. Surg.. 32, 291 .

Barrett, N. R. (1960). Lancet, 1, 293.

Campbell, E. J M and Howell, J. B. L. (1960). Brit. med. 7., 1, 458.

Gelin, L. E. (1961). Acta chir. scand., 122, 287.

Griffiths, H. W. C. (1960). 7. roy. Coll. Surg. Edinb., 6, 13.

Harley, H. R. S. (1961). Proc. roy. Soc. Med., 54, 558 .

Maloney, J. V., Schmutzer, K. J., and Raschke, E. (1961). 7. thorac. cardiovasc. Surg., 41, 291.

Sellors, T. H. (1961). Thorax, 16, 1.

\title{
Steroids in Treatment of the Nephrotic Syndrome in Adults*
}

\author{
H. GOTZE, $†$ M.D. ; W. T. E. MCCAUGHEY, $\ddagger$ M.D. ; R. A. WOMERSLEY,§ M.D., M.R.C.P.
}

Brit. med. F., 1964, 1, 351-354

The nephrotic syndrome in adults, as characterized by proteinuria, hypoproteinaemia, and oedema, has a multiple aetiology. Some of the diseases with which it may be associated are relatively easily defined, but there remain a large number of cases in which the renal lesion is not usually certain. Where specific therapy for a causative condition has not been available, treatment has generally been directed towards relieving the most prominent symptom, the oedema, either by the infusion of plasma-volume expanders, such as concentrated human serum albumin, or by promoting the loss of salt and water from the body by the use of diuretics, low-salt diets, and exchange resins. While these measures have often been successful in their objective, they have not been thought to influence the renal defect responsible for the heavy proteinuria, which is the primary cause of the oedema. A further difficulty in assessing the response of this condition to any form of treatment is the recognized fact that some cases will recover, with loss of proteinuria, either spontaneously or after any measure to reduce oedema.

The nephrotic syndrome in children has always had a better prognosis than that in adults, but with the introduction of adrenocorticotrophic hormone and cortisone therapy it became obvious that the remission rate was dramatically improved (Lange et al., 1957 ; Charlton et al., 1958 ; Arneil, 1961). Experience with this form of treatment in the adult is not only more limited but there is much less certainty of its effectiveness (Blainey et al., 1960 ; Burch et al., 1962 ; Sharpe and Unger, 1959).

We report here 26 cases of the nephrotic syndrome in adults treated with prolonged steroid therapy.

\section{Material and Methods}

A total of 26 patients have been treated, of whom 14 were males and 12 females, with ages from 15 to 58 years. All those selected for treatment had a proteinuria of above 3 g. In 24 hours, and hypoproteinaemia. Oedema had been present at some time in the course of the disease in all subjects, but wa not necessarily so when treatment was started. An elevated blood-pressure or blood urea was not regarded as a bar to treatment. In most cases the concentration of cholesterol in the serum was above normal. Only cases in which the nephrotic syndrome was diagnosed, either on renal biopsy or on clinical grounds, as being of unknown aetiology were included in the trial. The large number of unrelated diseases in which the nephrotic syndrome may occur as a complication were specifically excluded.

The patients were admitted to hospital for initial study and the commencement of steroid therapy. In the preliminary work and in the follow-up clinic, observations were made on the 24-hour excretion of protein in the urine, the plasma proteins, the blood urea, the clearance of endogenous creatinine, and the serum cholesterol. On discharge from hospital followup appointments were made at monthly intervals so far as practicable. The steroid used was prednisolone in all cases except one, when methylprednisolone was used. Two cases were started on methylprednisolone, but later were switched to prednisolone. The initial dose of prednisolone varied between 20 and $80 \mathrm{mg}$./day; thereafter the dose was in most cases altered according to the response obtained as judged by the degree of proteinuria. Where the level of protein excretion did not diminish, the dose of steroid was lowered in order to reduce toxic side-effects. The maintenance dose of prednisolone varied between 10 and $20 \mathrm{mg}$./day. All patients were on a high-protein diet, and if oedema was present salt restriction and diuretic therapy were used. Continuous prophylactic

* From the Department of Medicine and Pathology, the Queen's University of Belfast.

† British Council Scholar. ‡Lecturer, Department of Pathology. $\checkmark$ Senior Lecturer, Department of Medicine. 